\title{
Sleep duration and plasma leptin concentrations in early pregnancy among lean and overweight/ obese women: a cross sectional study
}

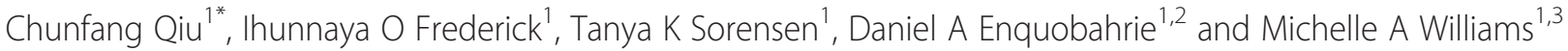

\begin{abstract}
Background: Early-pregnancy short sleep duration is predictive of gestational diabetes and preeclampsia; mechanisms for these associations are unknown. Leptin, an adipocyte-derived peptide involved in regulating food intake and energy expenditure, may play a role in these observed associations. Given inconsistent reports linking short sleep duration with leptin, and absence of studies among pregnant women, we examined the association of maternal sleep duration with plasma leptin in early pregnancy.

Methods: This cross-sectional study included 830 pregnant women. Plasma leptin was measured in samples collected around 13 weeks gestation. Sleep duration was categorized as: $\leq 5,6,7-8$ (reference), and $\geq 9$ hours. Differences in leptin concentrations across categories were estimated using linear regression. Analyses were completed for lean and overweight/obese women.

Results: Overall, women with long sleep duration had elevated plasma leptin ( $p$-value $=0.04$ ). However, leptin concentrations were not statistically significantly elevated in women with a short sleep duration. There was no association of leptin with sleep duration among lean women. Among overweight/obese women, a U-shaped relation between leptin and sleep duration was observed: Mean leptin was elevated ( $\beta=21.96 \mathrm{ng} / \mathrm{ml}, P<0.001$ ) among women reporting $\leq 5$ hour of sleep compared with reference group; and women reporting $\geq 9$ hours of sleep also had elevated leptin ( $\beta=4.29 \mathrm{ng} / \mathrm{ml}, \mathrm{P}=0.09$ ).

Conclusions: Short sleep duration, and to a lesser extent long sleep duration, were associated with elevated leptin among overweight/obese women. These data add some evidence to help understand mechanistic relationships of sleep duration with pregnancy complications.
\end{abstract}

Keyword: Leptin, Overweight, Obesity, Pregnancy, Sleep duration

\section{Background}

The worldwide prevalence of obesity has doubled since 1980 [1-3]; and this epidemic has been paralleled by a trend in reduced sleep duration $[4,5]$. Mounting evidence from both experimental and observational studies point to short sleep duration as a risk factor for obesity and obesity-related cardiometabolic disorders including metabolic syndrome, type 2 diabetes, and cardiovascular disorders [6,7]. Furthermore results from controlled metabolic studies show that sleep is an important modulator of

\footnotetext{
* Correspondence: Chun-fang.Qiu@Swedish.org

${ }^{1}$ Center for Perinatal Studies, Swedish Medical Center, 1124 Columbia Street, Suite 750, Seattle, WA 98104, USA

Full list of author information is available at the end of the article
}

neuroendocrine function, glucose metabolism and the secretion of appetite regulatory hormones.

Leptin, an adipocyte-derived hormone known to act on hypothalamic receptors to regulate fat mass, reduce food intake, increase energy expenditure, and stimulate thermogenesis $[8,9]$, has recently been proposed as one possible mechanistic link between decreased habitual sleep duration and increased risk of obesity. Two research groups have reported that shorter habitual sleep durations are associated with reductions in fasting plasma leptin concentrations and higher body mass index [10,11]. Additionally, a number of small clinical experimental studies reported decreases in plasma leptin following acute bouts of sleep restriction [12-19]. However, at least two studies have

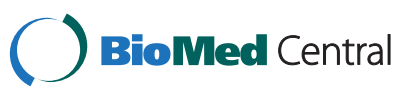

(c) 2014 Qiu et al.; licensee BioMed Central Ltd. This is an open access article distributed under the terms of the Creative Commons Attribution License (http://creativecommons.org/licenses/by/2.0), which permits unrestricted use, distribution, and reproduction in any medium, provided the original work is properly cited. 
reported no change in leptin [20,21]; and one study has reported increased leptin concentrations [22] following experimental sleep restriction. Hyperleptinaemia is also an important clinical risk factor for adverse pregnancy outcomes such as preeclampsia [23-25] and gestational diabetes mellitus [26]. At present, little is known about modifiable factors that influence leptin concentrations in maternal circulation during pregnancy.

Collectively, inference from these experimental studies, however, have been limited in part by their small sample size (with many having fewer than 12 participants), limited generalizability (with many restricted to healthy young males), and failure to account for changes in energy expenditure and caloric intake during the experimental periods of observations. Additionally, none of the earlier studies sought to evaluate the influence of habitual short sleep duration on leptin concentration in pregnant women. Given this gap in the literature, and given emerging evidence of increased risks of adverse pregnancy outcomes with habitual short sleep duration [27-29] and hyperleptinemia [23-26], we sought to evaluate the extent to which, if at all, maternal self-reports of habitual sleep duration during early pregnancy is associated with early pregnancy plasma leptin concentrations. Given emerging evidence suggesting that women and overweight/obese individuals may be particularly vulnerable to the physiological consequences of sleep restriction [22], we also examined the extent to which observed association differ by maternal prepregnancy lean or overweight/obesity status.

\section{Results}

Table 1 shows demographic characteristics of the 830 women in the study sample according to categories of reported habitual sleep duration during early pregnancy. Overall, maternal plasma leptin concentrations were correlated with systolic $(r=0.23)$, diastolic $(r=0.18)$, and mean arterial blood pressure $(r=0.22)$ (all p-values < 0.001- data not shown). Similarly, maternal plasma leptin concentrations were positively and statistically significantly associated with higher plasma glucose concentrations after a 50-gram oral glucose challenge screening test. Collectively, these correlations are consistent with earlier reports of associations of leptin with increased risks of preeclampsia [23-25] and gestational diabetes [26].

Mean leptin concentrations were slightly higher among groups of women classified as having short ( $\leq 5$ hours) and long ( $\geq 9$ hours) sleep duration during early pregnancy (Table 2). Mean leptin concentrations were lowest for women who reported sleeping 7-8 hours per night during early pregnancy (i.e., the reference group). Compared with the reference group, women who reported sleeping $\leq 5$ hours per night had a statistically non-significant elevation in plasma leptin (27.3 vs. $24.3 \mathrm{ng} / \mathrm{ml}$, p-value $=0.43$ ). Women who reported sleeping $\geq 9$ hours per night during early pregnancy, as compared with the reference group had elevated leptin concentrations $(27.0$ vs. $24.3 \mathrm{ng} / \mathrm{ml}$, p-value $=0.04$ ).

As shown in the bottom two panels in Table 2, the association between maternal sleep duration and leptin concentrations differed according to maternal pre-pregnancy lean and overweight/obesity status. After stratifying the study population according to lean (BMI $<25 \mathrm{~kg} / \mathrm{m}^{2}$ ) and overweight/obese women $\left(\geq 25 \mathrm{~kg} / \mathrm{m}^{2}\right)$, we noted no association of sleep duration with leptin concentrations among lean women. However, among overweight women, we noted a pronounced $\mathrm{U}$-shaped relationship between plasma leptin and sleep duration. Overweight/obese women who reported sleeping $\leq 5$ hours per night during early pregnancy had substantially higher plasma leptin concentrations as compared with those who reported sleeping 7-8 hours per night (58.3 vs. $38.2 \mathrm{ng} / \mathrm{ml}$, p-value $<0.001)$. Compared with women who reported sleeping 7-8 hours per night (i.e., the reference group), those women who reported sleeping $\geq 9$ hours per night had increased leptin concentrations, though the increase did not reach statistical significance $(43.0 \mathrm{vs} .38 .2 \mathrm{ng} / \mathrm{ml}$, p-value $=0.09)$. Given evidence of different associations of sleep duration with leptin concentration, all further analyses were completed for lean (BMI $<25 \mathrm{~kg} / \mathrm{m}^{2}$ ) and overweight/obese $\left(\geq 25 \mathrm{~kg} / \mathrm{m}^{2}\right)$ women separately.

As shown in Table 3, associations between leptin concentration and short sleep duration among overweight/ obese women remained after adjustment for potential confounding by maternal age, race/ethnicity, and marital status (Model 1). Notably, the associations remained statistically significant, though somewhat attenuated, after maternal pre-pregnancy BMI was included in the multivariable model (Model 2). After controlling for all confounders, short sleep duration during pregnancy ( $\leq 5$ hours per night) was associated with higher plasma concentrations on average (mean \pm stand error [SE] $21.96 \pm 5.30 \mathrm{ng} / \mathrm{ml}, \mathrm{p}<0.001$ ). The fully adjusted model explained $25 \%$ of the variance in leptin concentration (adjusted $R^{2}=0.25$ ). Overweight/ obese women who reported sleeping $\geq 9$ hours per night also had elevated mean leptin concentrations (mean $\pm \mathrm{SE}$ $4.29 \pm 2.62 \mathrm{ng} / \mathrm{ml}, \mathrm{p}=0.09$ ) though this association did not reach statistical significance. Consistent with univariate analyses, we observed no evidence of an association between sleep duration and leptin concentrations among lean women (BMI $<25 \mathrm{~kg} / \mathrm{m}^{2}$ ). Further adjusting for blood pressure in the 1st trimester did not change the estimates.

We next sought to further explore the curvilinear association between leptin concentrations and sleep duration according to sleep duration among overweight/obese women. There was a U-shaped relationship between hours of sleep and leptin concentrations during early pregnancy (Figure 1). However, the quadratic term for sleep duration was not statistically significant $(\mathrm{p}=0.18)$ in the adjusted 
Table 1 Sociodemographic characteristics of the study population $(\mathrm{N}=\mathbf{8 3 0})$ according to categories of self-reported nightly sleep duration during early pregnancy

\begin{tabular}{|c|c|c|c|c|}
\hline \multirow[b]{3}{*}{ Characteristics } & \multicolumn{4}{|c|}{ Categories of hours of sleep during pregnancy } \\
\hline & $\leq 5$ hours & 6 hour & 7-8 hours & $\geq 9$ hours \\
\hline & $\mathrm{N}=\mathbf{2 8}$ & $N=44$ & $\mathrm{~N}=485$ & $N=273$ \\
\hline Maternal age (years) & $29.6 \pm 5.6$ & $31.4 \pm 4.1$ & $32.0 \pm 4.5$ & $31.6 \pm 4.6$ \\
\hline $18-25$ & $6(21.4)$ & $3(6.8)$ & $23(4.7)$ & $9(3.3)$ \\
\hline $25-34$ & $16(57.1)$ & $33(75.0)$ & $331(68.3)$ & $193(70.7)$ \\
\hline$\geq 35$ & $6(21.4)$ & $8(18.2)$ & $131(27.0)$ & $71(26.0)$ \\
\hline \multicolumn{5}{|l|}{ Maternal race/Ethnicity } \\
\hline Non-Hispanic White & $26(92.9)$ & $37(84.1)$ & $417(86.0)$ & $236(86.5)$ \\
\hline African American & $0(0.0)$ & $3(6.8)$ & $10(2.0)$ & $3(1.1)$ \\
\hline Other & $2(7.1)$ & $4(9.1)$ & $58(12.0)$ & $34(12.4)$ \\
\hline \multicolumn{5}{|l|}{ Payment status } \\
\hline Insurance & $21(75.0)$ & $37(84.1)$ & $432(89.1)$ & $245(89.7)$ \\
\hline Medicaid & $4(14.3)$ & $3(6.8)$ & $9(1.8)$ & $10(3.7)$ \\
\hline Missing & $3(10.7)$ & $4(9.1)$ & $44(9.1)$ & $18(6.6)$ \\
\hline Nulliparous & $23(82.1)$ & $34(77.3)$ & $408(84.1)$ & $252(92.3)$ \\
\hline Not married & $11(39.3)$ & $6(13.6)$ & $54(11.1)$ & $27(9.9)$ \\
\hline$<12$ years of education & $3(10.7)$ & $1(2.3)$ & $27(5.6)$ & $10(3.7)$ \\
\hline Smoked during pregnancy & $3(10.7)$ & $2(4.6)$ & $30(6.2)$ & $19(7.0)$ \\
\hline Physically inactive during pregnancy & $8(28.6)$ & $5(11.4)$ & $81(16.7)$ & $46(16.9)$ \\
\hline Pre-pregnancy BMI & $23.0 \pm 4.8$ & $22.3 \pm 4.0$ & $23.2 \pm 4.8$ & $23.7 \pm 5.3$ \\
\hline \multicolumn{5}{|l|}{$\left(\mathrm{kg} / \mathrm{m}^{2}\right)$} \\
\hline$<18.5$ & $2(7.1)$ & $4(9.1)$ & $20(4.1)$ & $9(3.3)$ \\
\hline $18.5-24.9$ & $21(75.0)$ & $30(68.2)$ & $359(74.0)$ & $196(71.8)$ \\
\hline $25-29.9$ & $2(7.1)$ & $8(18.2)$ & $68(14.0)$ & $44(16.1)$ \\
\hline$\geq 30.0$ & $3(10.7)$ & $2(4.5)$ & $38(7.9)$ & $24(8.8)$ \\
\hline Mean systolic blood pressure in first trimester $(\mathrm{mmHg})$ & $114.2 \pm 10.4$ & $114.3 \pm 9.4$ & $112.5 \pm 10.0$ & $112.6 \pm 10.2$ \\
\hline Mean diastolic blood pressure in first trimester $(\mathrm{mmHg})$ & $69.2 \pm 6.3$ & $69.2 \pm 7.0$ & $70.3 \pm 7.2$ & $69.8 \pm 7.0$ \\
\hline Mean arterial blood pressure in first trimester $(\mathrm{mmHg})$ & $84.2 \pm 6.9$ & $84.2 \pm 7.0$ & $84.4 \pm 7.3$ & $84.1 \pm 7.2$ \\
\hline Gestational age at blood collection (weeks) & $12.9 \pm 3.0$ & $14.5 \pm 3.3$ & $13.7 \pm 3.5$ & $13.6 \pm 3.2$ \\
\hline
\end{tabular}

Data presented as mean \pm SD or number (\%).

model that includes maternal age, race, marital status and pre-pregnancy BMI.

\section{Discussion}

In this cross sectional study, we observed a U-shaped relationship between sleep duration and leptin concentrations during early pregnancy among overweight/obese women. In this population, women who reported sleeping $\leq 5$ hours per night had the highest plasma leptin concentrations in early pregnancy (even after additional adjustment for prepregnancy BMI). No such relationship was observed among lean women.

We are unaware of published reports concerning the association of sleep duration and leptin concentrations in pregnant women. Our findings, however, are in general agreement with results from some [22,30,31], though not all $[10,18,32]$, studies that have assessed leptin concentrations in relation to habitual sleep duration or acute sleep deprivation among men and non-pregnant women.

In an experimental study of 21 men and women (instructed to not change their usual diet and allowed to choose their meals from a standard meal), Pejovic and colleagues [30] found a 14\% increase in 24-hour leptin levels after one night of sleep deprivation. In a recent experimental study involving 136 participants exposed to 5 consecutive nights of restricted sleep (4 hours of time in bed), Simpson and colleagues noted that plasma leptin concentrations were statistically significantly increased during the sleep deprived state as compared with baseline values [22]. In stratified analyses the authors noted that increases in 
Table 2 Distribution of plasma leptin concentrations according to maternal self-reported nightly sleep duration during early pregnancy

\begin{tabular}{|c|c|c|c|c|}
\hline \multirow{2}{*}{$\begin{array}{l}\text { Early pregnancy } \\
\text { Plasma leptin (ng/ml) }\end{array}$} & \multicolumn{4}{|c|}{ Hours of sleep during pregnancy } \\
\hline & $\leq 5$ & 6 & $7-8$ & $\geq 9$ \\
\hline All women (N) & 28 & 44 & 485 & 273 \\
\hline \multirow[t]{2}{*}{ Mean \pm SD } & $27.3 \pm 19.7$ & $24.3 \pm 16.8$ & $24.3 \pm 17.1$ & $27.0 \pm 17.3$ \\
\hline & $\left(p^{*}=0.43\right)$ & $\left(p^{*}=0.98\right)$ & (Reference) & $\left(p^{*}=0.04\right)$ \\
\hline${ }^{* *}$ Lean women $(\mathrm{N})$ & 23 & 34 & 379 & 205 \\
\hline \multirow[t]{2}{*}{ Mean \pm SD } & $20.6 \pm 14.1$ & $19.9 \pm 13.6$ & $20.5 \pm 14.7$ & $21.7 \pm 13.4$ \\
\hline & $\left(p^{*}=0.98\right)$ & $\left(p^{*}=0.82\right)$ & (Reference) & $\left(p^{*}=0.31\right)$ \\
\hline${ }^{* *}$ Overweight/obese women (N) & 5 & 10 & 106 & 68 \\
\hline \multirow[t]{2}{*}{ Mean \pm SD } & $58.3 \pm 8.0$ & $39.1 \pm 18.8$ & $38.2 \pm 18.6$ & $43.0 \pm 18.2$ \\
\hline & $\left(p^{*}<0.001\right)$ & $\left(p^{*}=0.98\right)$ & (Reference) & $\left(p^{*}=0.09\right)$ \\
\hline
\end{tabular}

${ }^{*}$ Pair-wise T-test $\mathrm{p}$-value (each sleep duration group compared to reference group of 7-8 hours).

${ }^{* *}$ Lean women $\left(B M I<25 \mathrm{~kg} / \mathrm{m}^{2}\right)$; Overweight/Obese women $\left(\mathrm{BMI} \geq 25 \mathrm{~kg} / \mathrm{m}^{2}\right)$.

leptin concentrations were statistically significantly higher among women and participants with higher BMI as compared with men and those with lower BMI, respectively [22]. Our results are in agreement with these experimental studies, particularly those that assess sleep duration and leptin associations with consideration of possible heterogeneity according to BMI.
Our findings, however, are not in agreement with other earlier studies $[10,18,32]$. For example, in their short term partial sleep deprivation study, Spiegel and colleagues reported short sleep was associated with reduction in leptin concentrations among lean men on a controlled diet with constant glucose infusion [18]. Additionally, in a cross sectional analysis from data based on

Table 3 Relationship between maternal self-reported hours of nightly sleep duration and plasma leptin concentrations in early pregnancy: estimates linear regression coefficients for the participants of the Omega Study, Seattle and Tacoma, Washington, 1996-2000

\begin{tabular}{|c|c|c|c|c|c|c|c|c|c|}
\hline \multirow[t]{2}{*}{ Hours of sleep during pregnancy } & \multirow[t]{2}{*}{ N } & \multicolumn{4}{|c|}{ MODEL 1} & \multicolumn{4}{|c|}{ MODEL 2} \\
\hline & & $\beta$ & SE $(\beta)$ & $95 \% \mathrm{Cl}$ & P-value & $\beta$ & SE $(\beta)$ & $95 \% \mathrm{Cl}$ & P-value \\
\hline \multicolumn{10}{|l|}{ All women } \\
\hline$\leq 5$ & 28 & 4.38 & 3.76 & $(-2.99,11.76)$ & 0.24 & 4.77 & 2.88 & $(-0.89,10.43)$ & 0.10 \\
\hline 6 & 44 & -0.05 & 2.56 & $(-5.08,4.98)$ & 0.99 & 1.85 & 2.07 & $(-2.21,5.91)$ & 0.37 \\
\hline $7-8$ & 485 & Reference & & & & Reference & & & \\
\hline$\geq 9$ & 273 & 2.60 & 1.30 & $(0.04,5.16)$ & 0.05 & 1.77 & 1.05 & $(-0.30,3.83)$ & 0.09 \\
\hline Adjusted $R^{2}$ & & 0.02 & & & & 0.34 & & & \\
\hline \multicolumn{10}{|l|}{ Lean women } \\
\hline$\leq 5$ & 23 & 1.24 & 2.85 & $(-4.35,6.83)$ & 0.66 & 1.81 & 2.84 & $(-3.76,7.38)$ & 0.52 \\
\hline 6 & 34 & -0.58 & 2.36 & $(-5.23,4.06)$ & 0.81 & 1.47 & 2.26 & $(-2.96,5.91)$ & 0.51 \\
\hline $7-8$ & 379 & Reference & & & & Reference & & & \\
\hline$\geq 9$ & 205 & 1.10 & 1.18 & $(-1.22,3.42)$ & 0.35 & 0.86 & 1.09 & $(-1.28,3.00)$ & 0.43 \\
\hline Adjusted $R^{2}$ & & 0.02 & & & & 0.15 & & & \\
\hline \multicolumn{10}{|l|}{ Overweight/obese women } \\
\hline$\leq 5$ & 5 & 24.99 & 4.06 & $(16.97,33.01)$ & $<0.001$ & 21.96 & 5.30 & $(11.50,32.43)$ & $<0.001$ \\
\hline 6 & 10 & 1.40 & 5.47 & $(-9.39,12.20)$ & 0.80 & 3.95 & 4.86 & $(-5.63,13.53)$ & 0.42 \\
\hline $7-8$ & 106 & Reference & & & & Reference & & & \\
\hline$\geq 9$ & 68 & 4.61 & 2.88 & $(-1.07,10.30)$ & 0.11 & 4.29 & 2.62 & $(-0.87,9.46)$ & 0.09 \\
\hline Adjusted $R^{2}$ & & 0.07 & & & & 0.25 & & & \\
\hline
\end{tabular}

Separate models were fit for all, lean $\left(B M l<25 \mathrm{~kg} / \mathrm{m}^{2}\right.$ ), and overweight $\mathrm{BMI} \geq 25 \mathrm{~kg} / \mathrm{m}^{2}$ ) women, respectively.

Model 1: reported coefficients adjusted for maternal age, race/ethnicity, and marital status; and Model 2: Model $1+$ maternal pre-pregnancy body mass index.

$\beta$, Estimated coefficient; SE ( $\beta$ ), Standard error of the estimated coefficient; $95 \% \mathrm{Cl}, 95 \%$ confidence interval. 


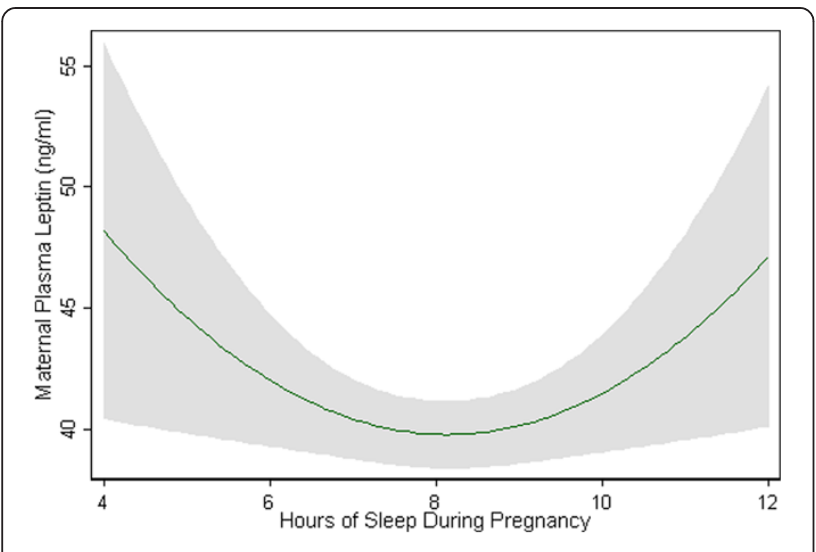

Figure 1 Two-way quadratic prediction plots with $95 \%$ confidence interval (gray shade) of predicted maternal plasma leptin concentrations (green line) according to hours of sleep during early pregnancy after adjusting for maternal age, race, marital status and pre-pregnancy BMI.

the Wisconsin Sleep Cohort, investigators observed reduced leptin concentrations in relation to reduced habitual sleep duration [10]. In a recent study of 80 obese men and pre-menopausal women, Knutson and colleagues observed no statistically significant associations of relative leptin level (leptin concentration divided by body fat percentage) with habitual sleep duration [32].

Several limitations merit discussion and consideration. First, the cross sectional design of our study and the fact that we did not directly measure maternal sleep duration during pregnancy limited our ability to infer the temporal relationship between sleep duration (or sleep quality), adipose tissue mass and plasma leptin concentrations in early pregnancy. Prospective studies of pregnant women that include objective measures of sleep duration and maternal adipose tissue mass are needed to demonstrate more conclusively these potential causal relationships. Second, a single measurement of plasma leptin may be susceptible to short-term variations, and thus is not likely to provide a time-integrated measure of maternal leptin status during early pregnancy. Consequently, results from our study, with only one measurement of plasma leptin, may have been biased. Longitudinal studies with serial measurements of maternal plasma leptin concentrations are needed to expand upon our current findings. Third, measurement error from the use of self-reported sleep duration is likely to have occurred. However, this error is unlikely to have systematically biased our findings, because the reporting error is not associated with the laboratory determination of maternal plasma leptin concentrations. Misclassification of maternal self-reported sleep duration (unrelated to our laboratory measures of maternal plasma leptin concentrations) would have served to underestimate the true association between the two covariates. Fourth, diurnal variation in leptin concentration may have influenced our results. Because subjects were recruited and enrolled while they attended obstetric clinics to receive standard prenatal care, and because prolonged fasting is contraindicated during pregnancy, we were restricted to measuring leptin in nonfasting blood samples. Finally, the limitation of the relative small sample size in the category of overweight or obese women having short sleep duration must be considered when interpreting our study results.

The identification of leptin as a regulated secreted peptide from adipocytes was a key development in the identification of adipose tissue as an endocrine organ [8]. Despite intense research, the precise metabolic and molecular mechanisms by which leptin secretion is regulated remain incompletely understood. Our findings along with those of others [22] suggest that sleep may have a role in regulation of leptin, particularly in overweight or obese individuals. Given the central role leptin plays in regulating energy homeostasis through central and peripheral mechanisms, and that pregnancy represents a period of profound alterations in glucose homeostasis and lipid metabolism, it stands to reason that factors (such as sleep duration) that may influence leptin concentrations in the non-pregnant state may also play a role during pregnancy. Our findings suggest that alterations in maternal leptin concentrations may be related to habitual sleep duration in early pregnancy. Evaluation of alterations in leptin concentrations according to changes in maternal sleep duration, for example, may be one way of objectively assessing the physiological impact of interventions designed to assess behavioral interventions designed to improve maternal sleep habits and sleep hygiene during pregnancy.

Hyperleptinaemia is an important clinical risk factor for preeclampsia [23-25] and gestational diabetes mellitus [26]. Both disorders are associated with maternal adult weight gain and pre-pregnancy weight gain [33-35]. At present, little is known about modifiable factors that influence leptin concentrations in maternal circulation during pregnancy.

\section{Conclusions}

Our findings suggest that sleep duration, a modifiable factor, and influences leptin concentrations in early pregnancy, particularly among overweight and obese women. If confirmed, improved sleep habits, resulting in improvements in sleep duration and quality, before and during pregnancy may well be one important component in lifestyle programs and strategies aimed towards disease prevention and health promotion in all populations, including pregnant women.

\section{Methods}

\section{Study design and population}

This analysis uses data initially gathered for the Omega Study, a prospective study designed to examine the 
metabolic and dietary predictors of preeclampsia, gestational diabetes, and other pregnancy outcomes. The study population was drawn from women attending prenatal care at clinics affiliated with Swedish Medical Center and Tacoma General Hospital in Seattle and Tacoma, Washington, respectively. Recruiting began in December 1996. Women who initiated prenatal care before 16 weeks gestation were eligible to participate. Women were ineligible if they were younger than 18 years of age, did not speak and read English, did not plan to carry the pregnancy to term or deliver at either of the two research hospitals, and/or were past 16 weeks gestation.

Enrolled subjects were asked to participate in an interview regarding sociodemographic and lifestyle characteristics and medical and reproductive histories. Non-fasting blood and urine specimens were collected, processed, and stored during early pregnancy. Pregnancy outcome information was abstracted from labor, delivery, and medical records after the estimated delivery date. The procedures used in this study were in agreement with the protocols approved by the Institutional Review Boards of Swedish Medical Center and Tacoma General Hospital. All participants provided written informed consent.

\section{Analytical population}

The analytical population is derived from participants who enrolled in the Omega Study between 1996 and 2000. During this period, 1,219 eligible women were approached, and 1,000 (82 percent) agreed to participate. A total of 91 women with pre-gestational chronic hypertension and/or multifetal pregnancies were excluded from the current analysis. Also excluded were 59 women with missing leptin concentration values, and 20 women with incomplete information on sleep duration during pregnancy. Thus, 830 women remained for analysis.

\section{Data collection and sleep duration assessment}

At the time of enrollment in the Omega study (12.7 weeks gestation, on average), a 45 to 60 minute structured questionnaire was administered by a trained interviewer. Information on maternal sociodemographic, medical, reproductive, and lifestyle characteristics including average number of hours of sleep during early pregnancy was collected. Maternal average nightly sleep duration during pregnancy was ascertained by asking women the following question: "Since becoming pregnant, how many hours per night do you sleep?" Responses were reported as integers. Following the epidemiological literature of sleep duration in adults, particularly available literature focused on pregnant women, we classified participants into 4 sleep duration categories: $\leq 5$ hours (short duration), 6 hours (intermediate duration), 7-8 hours (normal duration or reference group), and $\geq 9$ hours (long duration), respectively.

\section{Blood collection and plasma leptin measurements}

At or near the time of interview (13.2 weeks gestation, on average), a non-fasting blood sample was collected. Blood was drawn into lavender-top vacutainer tubes containing $\mathrm{K}_{3}$-EDTA $(1 \mathrm{mg} / \mathrm{ml})$. The tube was centrifuged at $850 \mathrm{~g}$ for 20 minutes at $4^{\circ} \mathrm{C}$ to separate red cells, white cells, and plasma. Fractions were aliquoted and stored at $-80^{\circ} \mathrm{C}$ until analysis. Plasma leptin concentrations were measured using an enzyme immunoassay (Diagnostic Systems Laboratory, Inc., Webster, Texas, USA) with the intra- and inter-assay coefficients of variation both $<8 \%$. All assays were completed without knowledge of maternal characteristics.

\section{Statistical analyses}

We examined the distributions of maternal sociodemographic, reproductive, and medical characteristics according to four sleep duration categories. We then examined distributions of plasma leptin concentrations and found them to be approximately normal. We therefore reported mean leptin concentrations across sleep duration categories. Spearman's rank correlation coefficients were calculated to quantify associations between maternal early pregnancy plasma leptin concentrations with first trimester systolic, diastolic and mean arterial blood pressure. Correlations were also estimated to quantify the association of leptin concentrations with plasma glucose concentration after a 50-gram oral glucose challenge.

Multivariable linear regression analyses with robust variances [36] were performed to evaluate the association between sleep duration categories and plasma leptin concentrations. To assess confounding, we entered covariates in Table 1 into a linear regression model sequentially, and then compared the unadjusted and adjusted regression coefficients for sleep duration categories [37]. Final models included covariates that altered unadjusted coefficients for by $10 \%$ or more, as well as covariates of $a$ priori interest (i.e., maternal age). The following covariates were considered as confounders in the final models: maternal age $(<25,25-34$, and $\geq 35$ years), race/ethnicity (White, African American, and Other), marital status (married vs. not married) prepregnancy body mass index (BMI). Smoking was found not to be the confounder in this analysis. To assess the potential modifying effects of maternal lean $\left(<25 \mathrm{~kg} / \mathrm{m}^{2}\right)$ and overweight/obesity $\left(\geq 25 \mathrm{~kg} / \mathrm{m}^{2}\right)$ status on the relationships between sleep duration and leptin concentrations, we fit separate linear regression models for each group. We also fit linear regression models with interaction terms between sleep duration and maternal pre-pregnancy BMI. Adjusted $R^{2}$ values were calculated to measure the explanatory power of each model, adjusted for degrees of freedom.

Next, to examine the nonlinear relationship of plasma leptin concentrations and sleep duration in overweight pregnant women, we treated the sleep hours as continuous variable and fit a quadratic model by adding a 
quadratic term (sleep hours squared) plus a linear term in the regression models. All analyses were performed using Stata 9.0 statistical software (Stata, College Station, Texas, USA). All continuous variables are presented as mean \pm standard deviation (SD), unless otherwise specified. All reported p-values are two-tailed.

\section{Details of ethics approval}

The local institution as stated in the Methods section has approved human experimentation. Institutional Review Board \#2505S-94 (Continuing Review Progress Report) was obtained on 12-20-2011. The written consent has been obtained from all patients participating in current study.

\section{Competing interest}

The authors declare that they have no competing interests.

\section{Authors' contributions}

CQ and MAW had full access to all the data in the study and take responsibility for the integrity of the data, the accuracy of the data analysis, and the decision to submit for publication. CQ analyzed the data. CQ and MAW drafted the manuscript. IOF, TKS and DAE reviewed and edited the manuscript. MAW conceived, designed and obtained funding for the study. All authors interpreted the data, critically revised the draft for important intellectual content, and gave final approval of the manuscript to be published.

\section{Acknowledgments}

The authors are grateful for the technical expertise of staff of the Center for Perinatal Studies, Swedish Medical Center.

\section{Funding}

This work was supported, in part, by grants from the National Institutes of Health (R01-HD-055566 and R01-HD-32562). Dr. Enquobahrie was supported by a grant from the National Heart, Lung and Blood Institute (K01-HL-103174).

\section{Author details}

${ }^{1}$ Center for Perinatal Studies, Swedish Medical Center, 1124 Columbia Street, Suite 750, Seattle, WA 98104, USA. ²Department of Epidemiology, School of Public Health, University of Washington, Seattle, WA, USA. ${ }^{3}$ Department of Epidemiology, Harvard School of Public Health, Boston, MA, USA.

Received: 8 April 2013 Accepted: 3 January 2014

Published: 9 January 2014

\section{References}

1. Finucane MM, Stevens GA, Cowan MJ, Danaei G, Lin JK, Paciorek CJ, Singh GM, Gutierrez HR, Lu Y, Bahalim AN, Farzadfar F, Riley LM, Ezzati M, Global Burden of Metabolic Risk Factors of Chronic Diseases Collaborating Group (Body Mass Index): National, regional, and global trends in body-mass index since 1980: systematic analysis of health examination surveys and epidemiological studies with 960 country-years and $9 \cdot 1$ million participants. Lancet 2011, 377:557-567.

2. Institute of Medicine: Sleep disorders and sleep deprivation: an unmet public health problem. Washington, DC: The National Academies Press; 2006.

3. Ram S, Seirawan H, Kumar SK, Clark GT: Prevalence and impact of sleep disorders and sleep habits in the United States. Sleep Breath 2010, 14:63-70.

4. Centers for Disease Control and Prevention: Unhealthy sleep-related behaviors - 12 states, 2009. MMWR 2011, 60:234-238.

5. Beccuti G, Pannain S: Sleep and obesity. Curr Opin Clin Nutr Metab Care 2011, 14:402-412.

6. Morselli L, Leproult R, Balbo M, Spiegel K: Role of sleep duration in the regulation of glucose metabolism and appetite. Best Pract Res Clin Endocrinol Metab 2010, 24:687-702.

7. Knutson KL: Sleep duration and cardiometabolic risk: a review of the epidemiologic evidence. Best Pract Res Clin Endocrinol Metab 2010, 24:731-743.
8. Zhang Y, Proenca R, Maffei M, Barone M, Leopold L, Friedman JM: Positional cloning of the mouse obese gene and its human homologue. Nature 1994, 372:425-432.

9. Halaas JL, Gajiwala KS, Maffei M, Cohen SL, Chait BT, Rabinowitz D, Lallone RL, Burley SK, Friedman JM: Weight-reducing effects of the plasma protein encoded by the obese gene. Science 1995, 269:543-546.

10. Taheri S, Lin L, Austin D, Young T, Mignot E: Short sleep duration is associated with reduced leptin, elevated ghrelin, and increased body mass index. PLoS Med 2004, 1:e62.

11. Chaput JP, Després JP, Bouchard C, Tremblay A: Short sleep duration is associated with reduced leptin levels and increased adiposity: Results from the Quebec family study. Obesity (Silver Spring) 2007, 15:253-261.

12. Gomez-Merino D, Chennaoui M, Drogou C, Bonneau D, Guezennec CY: Decrease in serum leptin after prolonged physical activity in men. Med Sci Sports Exerc 2002, 34:1594-1599.

13. Gomez-Merino D, Drogou C, Chennaoui M, Tiollier E, Mathieu J, Guezennec $\mathrm{CY}$ : Effects of combined stress during intense training on cellular immunity, hormones and respiratory infections. Neuroimmunomodulation 2005, 12:164-172.

14. Guilleminault C, Powell NB, Martinez S, Kushida C, Raffray T, Palombini L, Philip P: Preliminary observations on the effects of sleep time in a sleep restriction paradigm. Sleep Med 2003, 4:177-184.

15. Gundersen Y, Opstad PK, Reistad T, Thrane I, Vaagenes P: Seven days' around the clock exhaustive physical exertion combined with energy depletion and sleep deprivation primes circulating leukocytes. Eur J Appl Physiol 2006, 97:151-157.

16. Mullington JM, Chan JL, van Dongen HP, Szuba MP, Samaras J, Price NJ, Meier-Ewert HK, Dinges DF, Mantzoros CS: Sleep loss reduces diurnal rhythm amplitude of leptin in healthy men. J Neuroendocrinol 2003, 15:851-854.

17. Nindl BC, Rarick KR, Castellani JW, Tuckow AP, Patton JF, Young AJ, Montain SJ: Altered secretion of growth hormone and luteinizing hormone after $84 \mathrm{~h}$ of sustained physical exertion superimposed on caloric and sleep restriction. J Appl Physiol 2006, 100:120-128.

18. Spiegel K, Leproult R, L'hermite-Balériaux M, Copinschi G, Penev PD, van Cauter E: Leptin levels are dependent on sleep duration: relationships with sympathovagal balance, carbohydrate regulation, cortisol, and thyrotropin. J Clin Endocrinol Metab 2004, 89:5762-5771.

19. Spiegel K, Tasali E, Penev P, van Cauter E: Brief communication: Sleep curtailment in healthy young men is associated with decreased leptin levels, elevated ghrelin levels, and increased hunger and appetite. Ann Intern Med 2004, 141:846-850.

20. Nedeltcheva AV, Kilkus JM, Imperial J, Kasza K, Schoeller DA, Penev PD: Sleep curtailment is accompanied by increased intake of calories from snacks. Am J Clin Nutr 2009, 89:126-133.

21. Schmid SM, Hallschmid M, Jauch-Chara K, Born J, Schultes B: A single night of sleep deprivation increases ghrelin levels and feelings of hunger in normal-weight healthy men. J Sleep Res 2008, 17:331-334.

22. Simpson NS, Banks S, Dinges DF: Sleep restriction is associated with increased morning plasma leptin concentrations, especially in women. Biol Res Nurs 2010, 12:47-53.

23. Williams MA, Havel PJ, Schwartz MW, Leisenring WM, King IB, Zingheim RW, Zebelman AM, Luthy DA: Pre-eclampsia disrupts the normal relationship between serum leptin concentrations and adiposity in pregnant women. Paediatr Perinat Epidemiol 1999, 13:190-204.

24. Poston L: Leptin and preeclampsia. Semin Reprod Med 2002, 20:131-138.

25. Ning Y, Williams MA, Muy-Rivera M, Leisenring WM, Luthy DA: Relationship of maternal plasma leptin and risk of pre-eclampsia: a prospective study. J Matern Fetal Neonatal Med 2004, 15:186-192.

26. Qiu C, Williams MA, Vadachkoria S, Frederick IO, Luthy DA: Increased maternal plasma leptin in early pregnancy and risk of gestational diabetes mellitus. Obstet Gynecol 2004, 103:519-525.

27. Williams MA, Miller RS, Qiu C, Cripe SM, Gelaye B, Enquobahrie D: Associations of early pregnancy sleep duration with trimester-specific blood pressures and hypertensive disorders in pregnancy. Sleep 2010, 33:1363-1371.

28. Qiu C, Enquobahrie D, Frederick 1O, Abetew D, Williams MA: Glucose intolerance and gestational diabetes risk in relation to sleep duration and snoring during pregnancy: a pilot study. BMC Womens Health 2010, 10:17.

29. Chang JJ, Pien GW, Duntley SP, Macones GA: Sleep deprivation during pregnancy and maternal and fetal outcomes: is there a relationship? Sleep Med Rev 2010, 14:107-114. 
30. Pejovic S, Vgontzas AN, Basta M, Tsaoussoglou M, Zoumakis E, Vgontzas A, Bixler EO, Chrousos GP: Leptin and hunger levels in young healthy adults after one night of sleep loss. J Sleep Res 2010, 19:552-558.

31. Omisade A, Buxton OM, Rusak B: Impact of acute sleep restriction on cortisol and leptin levels in young women. Physiol Behav 2010, 99:651-656.

32. Knutson KL, Galli G, Zhao X, Mattingly M, Cizza G, NIDDK Sleep Extension Study: No association between leptin levels and sleep duration or quality in obese adults. Obesity (Silver Spring) 2011, 19:2433-2435.

33. Hedderson MM, Williams MA, Holt VL, Weiss NS, Ferrara A: Body mass index and weight gain prior to pregnancy and risk of gestational diabetes mellitus. Am J Obstet Gynecol 2008, 198:409.

34. Rudra CB, Sorensen TK, Leisenring WM, Dashow E, Williams MA: Weight characteristics and height in relation to risk of gestational diabetes mellitus. Am J Epidemiol 2007, 165:302-308.

35. Frederick IO, Rudra CB, Miller RS, Foster JC, Williams MA: Adult weight change, weight cycling, and prepregnancy obesity in relation to risk of preeclampsia. Epidemiology 2006, 17:428-434.

36. White $\mathrm{H}$ : Heteroskedasticity-consistent covariance matrix estimator ad a direct test for heteroskedasticity. Econometrica 1980, 48:817-838.

37. Rothman KJ, Greenland S: Modern epidemiology 2nd edition. Philadelphia, Pennsylvania, USA: Lippincott-Raven Publishers; 1998:311-316.

doi:10.1186/1756-0500-7-20

Cite this article as: Qiu et al: Sleep duration and plasma leptin

concentrations in early pregnancy among lean and overweight/obese women: a cross sectional study. BMC Research Notes 2014 7:20.

\section{Submit your next manuscript to BioMed Central and take full advantage of:}

- Convenient online submission

- Thorough peer review

- No space constraints or color figure charges

- Immediate publication on acceptance

- Inclusion in PubMed, CAS, Scopus and Google Scholar

- Research which is freely available for redistribution 